\title{
WORK-INTEGRATED-LEARNING: SO, WHAT? A FRAMEWORK FOR DESCRIBING THE LEVEL OF INTEGRATION BETWEEN WORK AND LEARNING
}

\author{
L. Bernhardsson, M. Gellerstedt, T. Winman \\ University West (SWEDEN)
}

The knowledge society of today is characterized by a continuously ongoing technological development and digitalization that steadily calls for new competencies and transforms existing professions. For being able to provide up-to-date competence in a fast-changing labor market there is, perhaps more than ever, a need for extensive cooperation between Universities and surrounding society. A number of different models supporting the civic university has been established, e.g. "entrepreneurial university", the triple-helix model and the increasingly popular adoption of "work-integrated learning" (WIL).

Work-integrated learning offer students authentic learning experiences and create synergy between theory and practice, e.g. by cooperative educational programs, internship, sandwich programs and case based teaching. Beyond the pedagogical benefits with experiential learning, WIL also supports the transfer between higher education and work, i.e. increases readiness, employability and also encourage a more agentic engagement. Furthermore, research results show that WIL-students have career benefits regarding salary in early career and job advancement. Even though, WIL and similar strategies for combining theory and practice seems to have promising pedagogical and career advantages, the theoretical underpinning is still underdeveloped. For instance, the methodology for how learning is promoted and which role external partners could play is vague.

At University West with more than 25 years' experience of WIL a holistic approach to WIL have been adopted and WIL permeates all the Universities activities: education, research and extensive collaboration with the surrounding society. Over the years our efforts have been formalized and a taxonomy for will-activities have been developed. In sum, we know that WIL have promising potential, and we know what to do. But, in a recently performed study at this University, based on focus groups interviews and consolidation of our experiences we identified that even if the question "what?" is responded to, there is an important sub-question to be addressed, namely: "so what?". When adopting different WIL activities, both small and large scale activities, e.g. a guest lecture or an internship, it is reasonable to reflect on whether these activities are used in an optimal way? What kind of impact does the WIL-activity imply? What could be achieved by successful integration between theory and practice? Could it be visualized?

Inspired by models used for integrating technique in education (RAT, SAMR and TPCK-models), we have developed a framework for the progression of work-integrated learning in education. The framework is in a sense a model for "Wil-value". This framework could be used on different levels and in different context: in a single course, educational program, in research projects, cooperation with surrounding society, mentorship and on partner workplaces.

Keywords: WIL, work-integrated learning, digitalization, framework.

\section{INTRODUCTION}

Higher education plays a new role in the society and the highly specialized labor market, and higher education institutes are expected to interact with and contribute to the surrounding society [1-3]. University West in Sweden is since 2002 commissioned by the government to develop the pedagogical strategy called work-integrated learning (WIL) and WIL is the "trade mark" for the University. This means that pedagogical methods are based on WIL and that the faculty is working on further refinement and development in order to maximize the pedagogical gain offered by using the synergy between theory and practice. Furthermore, the university is pro-active in research and development projects aiming at developing learning at workplaces and action research is a common approach, i.e. making research, together with practitioners. Since 2011 it is possible to take a doctoral degree in with specialization in WIL.

Already 25 years ago, University West, took one of the first initiatives for supporting WIL, namely the adoption of Cooperative education (Co-op), where courses are sandwiched with periods of paid work. Naturally, Co-op is not the one and only strategy for WIL, even though it is an important part. 
Adopting WIL as a pedagogical philosophy has already from the beginning been, and is still, an ongoing process. Changing traditional teaching and habits, takes time, but over the year WIL has become more and more accepted and various strategies for adopting WIL have emerged. A taxonomy for how class rooms activities for supporting WIL has been developed [4]. This taxonomy, covers the following four categories: "using practice as inspiration" by using e.g. case methodology or practice based simulations, "bringing practice to class", e.g. guest lectures or using work life material like professionally developed programing code, annual reports and so forth. Thirdly, "utilizing professional tools", e.g. using the same software as companies or adopting industry standard for working processes. Lastly, "bringing class to practice" by different forms of field work, project works, thesis work, and longer co-op periods. Roughly half of all class rooms activities could be classified as belong to one of these four categories [ibid].

The PhD-program is also based on WIL not only as an aim for the research projects, but also as a pedagogical approach. The most frequent research method is action research and the pedagogical approach underpinning the program is also based on WIL, with an emphasis on learning outcomes important for being a researcher. For instance, different research methods are not divided into separate courses (e.g. qualitative vs quantitative methods), instead the course is based on the research process, from formalizing a research question to presentation of result, in order to mimic a more realistic research process in practice. More explicit examples of how WIL is practiced in undergraduate courses, PhD-program and in research programs is described elsewhere [4]. In an ongoing research project, a preliminary result indicates that slightly more than half $(53 \%)$ of the universities course syllabuses (nearly 800 courses studies) have an explicit section describing WIL.

\section{PROBLEM - WHAT IS NEEDED FOR FURTHER DEVELOPMENT?}

As indicated below, implementing an overall pedagogical philosophy in an organization is a process, and as all organizational changes, it takes time to find acceptance, support and to develop new ways of thinking and acting. But, after 25 years, our descriptive studies shows that WIL permeates all our activities; teaching, researching and our third mission. Our shows vibrant activities and rich variety of activities, visible in syllabuses, used in classroom and as an approach for cooperation with surrounding society. However, the University has the commitment, not only to adopt WIL as a pedagogical philosophy, but also to do research, evaluate and further develop WIL.

Thus, an important question at this stage was to find out requirements for taking the next step. What is needed in order to further develop WIL?

\section{FOCUS GROUP}

The collection of ideas and discussions about how the progression of AIL can be developed has been implemented in four focus groups. These groups represent the university as a whole and consist of students, Phd students, teachers and management. All groups had a matrix as a basis for initial discussions. This matrix has on one axis context of activity and on the second constellation of participation in the event. In the matrix highlighted activities are performed and it becomes clear how many variants of activities that can be developed.

\begin{tabular}{|c|c|c|c|c|c|}
\hline & $5^{\text {single }}$ & by & $18 g^{\text {Twins }}$ & Heforoup & Wy chass \\
\hline Coop & $x$ & & & & \\
\hline Internship & $x$ & & & & \\
\hline Social & & & & & \\
\hline Project & & & & $x$ & \\
\hline Reversed & & & & & $x$ \\
\hline Examwork & $x$ & $x$ & $?$ & & \\
\hline
\end{tabular}




\subsection{Students}

Students' interpretation of AIL corresponds much with official texts communicated from school. More of students descriptions are directly taken from the university's marketing concept and is more a description of what AIL teaching can be and not so much visions about how they would like activities designed. The students point out AIL as a way to connect theory and practice, and that they be given to contacts with industry during their studies. Several focus group wishes that the amount of activities related to the society should be increased.

\subsection{Phd students}

Phd students, all studying in education and informatics focusing on AIL, expressed the need to focus and define the result and purpose of the various activities and educational intentions. In addition to finding progression and the opportunity to find ways for the examination of WIL activities, it is important to raise the profile of learning that are not assessed, e.g. the student learns that was not the purpose. To find ways for students to reflect on their experiences in connection with the activities that are not directly related to learning objectives to do.

To develop ail we need to look at the concept / phenomenon from different perspectives, which takes place outside the university or college. Today is also seen ail as a concept which is much linked to external operations and their personnel, especially in the work of graduate students are writing and researching. Rarely is the focus on students' perceptions and experiences that may be important to take advantage. By raising and visibility even these parts, there may be a change in the upcoming activities that may involve a form of progression. The progression is important when there is meaningful when there is repetition of the same things that do not differ from the previous activity.

\subsection{Teachers}

The group of teachers felt that the concept of WIL and its activities are very complex and contain many different elements. They gave examples of activities where one currently is based on the second, and then can be seen as a form of progression. They believe that the focus should be on what is being done and to create differences between different activities. For example, a guest speaker, replacing a regular teacher's lecture is seen as WIL when students experience a contact with reality and the business community. But if the guest speakers will return on several occasions, the activities must bring something more than just meet someone from "outside" of the university. Similarly needed change in activities when students themselves meet the business community through various activities or when teachers meet business, for example through commissioned, and use their experiences from these opportunities in education.

\subsection{Management}

Respondents in this group consisted of people from the administration and research management. The group talked a lot about the value of change between WIL and activities that change progression. Visits to the workplace can be a first contact but rarely the development of knowledge in the profession of the study visits only repeated the number. The aim must be to learn new and more at every opportunity where students and working life meet.

One way to understand how it can be done may be to increase research on AIL in collaboration with alumni who participated in education where various forms of AlL been part of teaching. Teaching staff's experiences of different activities can also help to create change and development of the activity the execution and targets and thereby facilitate progression.

\section{RESULT}

One of the most crucial discussions in the focus groups concerned how WIL-activities could be evaluated. What constitutes a successful WIL-activity? The lack of a model for how to evaluate WIL makes it difficult to discuss further development. What does the activity offer in its present form and what could be achieved by refining the activity, and how? It seems like, we now know what and how WIL is adopted at the University. But, we cannot say, that we have a good answer to the question "so what?" We have very much focused on measuring quantity rather than quality of WIL.

Consequently, we conclude that the next step must be to focus on how adopted WIL could be evaluated. A system for evaluating WIL is a necessary requirement for addressing a number of 
important questions. Which strategies are the most successful? How could different strategies be optimized?

We believe that the best teaching and learning higher education environments encourage students to develop confidence in their own creative abilities and to develop a sense an ethical responsibility allied to comprehension that learning is a lifelong phenomenon that demands a lifelong curiosity and commitment. That is in line with [6] who said that "Were all instructors to realize that the quality of the mental process, not the production of correct answers, is the measure of educative growth, something hardly less than a revolution in teaching would be worked". But one must also remember what Michael [7] said regarding most common models of teaching at higher level "fundamentally, higher education is still a process of imparting knowledge by means of lectures ions/// but the context in which higher education takes place has changed - and changed dramatically."

We live in a rapidly changing, globalized and increasingly digitalized word where students need the kind of education that enables them to engage articulately as committed, active, thinking, global citizens as well as actors in the ethical, sustainable development of our societies and organizations. The society has invested a considerable amount of confidence and recourses in higher education systems, where quality is taken for granted. Simultaneously the individual invests both effort and recourses like time and money in his or her higher education, also with the confidence of an education system that is built on a fundament of quality. The belief is that higher education's qualitative teaching develops the students' knowledge that in turns makes them adaptable, assured, innovative and employable in the changing world. But if the student receives a poor or mediocre teaching he or she has wasted a lot of time and, just as the society has.

But what is quality in higher education? Good teaching quality can be defined in a variety of ways depending on what perspective that is assumed. Here we present just four of them, namely in relation to a) achievement of goals, b) the student's transformation process, c) the value added of the education and d) the evidence base for the form and content of the education. These different ways of looking at quality are largely compatible, but can also conflict with each other.

In this article, we focus on quality in teaching and learning based on the latter perspective, i.e. teaching quality as evidence-based education. We are very conscious that it is not the only way to define education quality, it rather is only a subset of what can be called education quality. We see education quality as something broader, something that covers the importance of entire education structures, such as educational programs that are offered, program design, eligibility and exam questions and evaluations, but it falls outside of this article, or is discussed in passing.

From a WIL-perspective qualitatively good teaching is only good to the extent that it is informed by the latest research, which means that learning processes and learning objects are intervened with each other, and concerns all participants. A good teacher, just like a good student, must also be considered as a learner, with the right and obligation to put questions and to be a critical thinker. The good teacher aims to help the student be confident in handling each learning object and to be open for new ideas, and seek new solutions and opportunities to problems and dilemmas. Therefore, from a WILperspective, we do not put the student in focus; we rather put learning in focus, which involve different actors with different mandates and opportunities in a joint process of learning. Throughout education, meaning-making processes are made where all participants' interest and ability to handle different situations are deepened through the development of, and about, different knowledge domains.

But just the fact that participants' are applying previously acquired abstract principles and mental models when they are confronted with new problems become insufficient to understand learning. Mostly because such a perspective does not include how the dealings are rooted in concrete situations, nor how each activity itself transforms the terms of new interpretations in continued action. From a WIL-perspective it is interesting to understand both what and how participants learn to handle different situations based on what they themselves define / perceive as the purpose of the activity, and their own role and how they understand the situation.

In order to understand how people learn, we see learning as processes that lead to increased participation in the central tasks of the activity [8], which also implies that learning thus has a direction, a movement from a periphery towards an increasingly involved participation in the central tasks of an activity. And it is by moving the lens from the student to see them as participants, the relationship with other actors in the situation / activity can be noted. 
If we for example consider internship, a professional practice is not something that individuals unilaterally adapt to. On the contrary, each action and activity need to be understood based on how both the participants and the practitioners they are involved in change, e.g. learning is a joint process.

Neither of the WIL-activities mention above guarantee increased learning per se. For instance, co-op education is not efficient per se, it depends on several factors: co-operation between the academic supervisor and mentor at the work place, how theory are being used, discussed and evaluated in practice, and how the practical experiences are discussed and used pedagogically both during the internship period and when students finally arrives back to campus. There is certainly a call for more knowledge about the merits with co-op [9] and other WIL-strategies. Another, example could a smaller initiative, like inviting a guest lecturer. How could we optimize the "WIL-value" in such an activity? Previous research suggest that qualities for being a proactive and agentic learner in higher education are the very same abilities required for effective professional practice [10] which makes it important to study learning processes and foster sound agentic learners, with a proficiency in intertwining theory and practice.

Naturally, coworkers striving with new innovative ways of developing WIL-activities are in a need for measuring the gain with their efforts. Coworkers wants to know the potential WIL-value with different activities and how to optimize these activities in order to reach the full potential. To evidence base effects of WIL and to further develop and fine-tune Wil-activities is also a part of the commission given to the University.

The aim with this article is to suggest a framework for "WIL-value" or "WIL-progression" and to discuss how this could be used as a support for refining WIL.

\section{IDE (FOUNDATION FOR OUR SUGGESTED FRAMEWORK)}

In discussions with the various focus groups draws on different models and taxonomies of learning. Some of the models is the introduction of technology to support learning and the group has talked about how these models can be used for thoughts on the introduction of WIL in teaching. Technology that supports learning, in our thoughts has been replaced by WIL activities to support learning. The PhD- group expresses the need to focus on what is being done, the process itself, in an equivalent manner to the outcome.

\subsection{SOLO taxonomy}

SOLO taxonomy was introduced by John Biggs [11] and gives a teacher the opportunity to make a student's learning visible in a structured way. He believes that the Structure of the Observed Learning Outcome shows the complexity of the learning by describing the learning that can be observed in terms of quality. By describing the learned through different qualitative verbs, they can be divided into different progression levels. The lowest level "pre-structural" means that the student fails to adequately address the issue. If the student success with addressing the issue it is called "uni-structural" (focusing on one single aspect) or "multi-structural" (several aspects included). If the student understand the topic adequately the different aspects should be integrated into a coherent whole, a level called "relational". And, in case the student also success with taking the whole into a higher level of abstraction, e.g. making generalizations, the highest level of progression called "extended abstract" is reached.

With this model as inspiration, we believe that it may be possible to create taxonomy for progression between different activities within WIL.

\subsection{RAT model}

Joan Hughes [12] has created a model that describes three qualitatively different steps in introducing technology in teaching and learning. The use of technology can be described as replacement, amplification and transformation, The RAT model.

The introduction of technology in teaching can be used to replace an earlier non-technology-based process. It can also increase productivity and efficiency in the same process through the use of the opportunities offered by the technology. It allows for something that is more, larger, or more detailed than when technology only replaces the manual processes. When the technology allows for change, restructuring reorganization or maybe even brand new, she calls it for Transformation. 
The model is perceived as relative simple to transform into a model where technology is replaced by activities on the subject of work-integrated learning. The model is understandable and it is easy to see the meaning of the concepts even when technology is changed to WIL. An activity outside the university can replace an in house activity. Then create an additive activity that insists learning to bury in the third step with an activity that also changes. Perhaps not only does learning change, but also the syllabus where activities are part of the teaching.

\subsection{SAMR model}

The Substitution Augmentation Modification Redefinition model (SAMR) was introduced by Ruben Puentedura is a four-level model for selecting, using, and evaluating technology in education [13].

Hamilton et.al. [14] argue for a clearer focus on the tasks and its levels in differences give a greater value to the model. The model can also inspire thoughts on how to add AIL as a tool in teaching to create learning. By considering the differences in the different steps, it is easy to see the possibilities of creating progression between different activities and their purposes. If the first activity is intended to replace another activity, the next one can have an extended purpose that helps to increase the learning and understanding. In the next step or activity, the AIL element must aim at creating a new thinking in order to, in the fourth step, aim and change the content itself. This can be done through adjustments in the syllabus content that take into account the students' learning in step four. These experiences become a content for subsequent students.

\section{SUGGESTED FRAMEWORK}

To optimize WIL activities, we recommend a model that can serve as support for what can be achieved with WIL activities. The model could also be used in evaluations of activities, course contents and syllabus. The model is based on four different steps that qualitatively differ from one another, starting with developing WIL and its activities to restore knowledge from activities to help transform the curriculum and course content. Below is one of several possible examples. We have chosen a business economics course that includes several different WIL activities.

Exchange: If we consider a course in business administration, a guest lecturer from the business community can replace the regular teacher. Students can perceive such an exchange as a qualitative development of the course.

Enlarge: If the guest lecturer then uses concrete examples and cases from his everyday life and not only focuses on theory, it becomes a magnification. Examples may be previous financial statements, dispositions and analyzes. This level is qualitatively higher than just a theory lecture and provides good conditions for learning.

Extend: When the activity can be carried out directly adjacent to a workplace and with concrete cases, quality and complexity can be further increased. In such a case, the student processes current economic facts, dispositions and analyzes. When the student is in concrete context, further steps are taken in the qualitative staircase and the activity can be seen as extended.

Evolve: The student's active participation in activities related to specific learning objectives can create new knowledge that sometimes contains knowledge with the aim of the course to convey. When the student then brings these knowledge back to the university, both the course, teachers and students can evolve and add new content to a course and may also involve an adjustment of the course syllabus. 


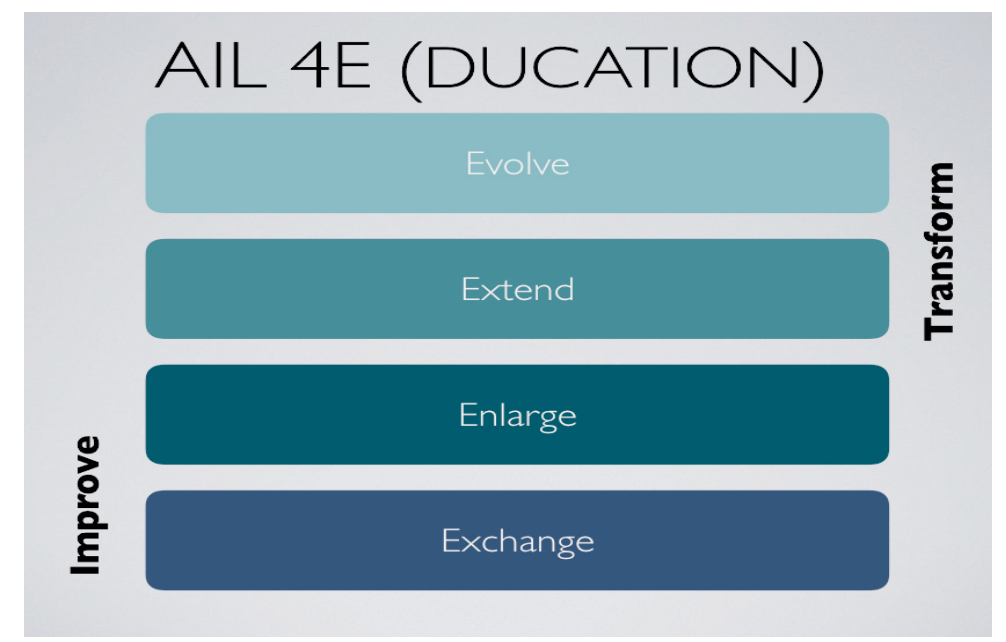

By actively using the model and as a description of learning outcomes for the activities use active verbs, we believe we can achieve better integration between work and learning. The different qualitative levels provide a clearer description of progression and provide increased opportunities for learning with clear connection to working life.

\section{DISCUSSION AND CONCLUSION}

The overall aim of this paper is to suggest a framework for how to assess the WIL-value and discuss how this could be used as a support for refining WIL-activities. The theoretical approach to learning that we have adopted implies that learning takes place in social activities, and as seen in the models and taxonomies of learning, involves different technologies, actors with different experiences, recourses and ambitions, meet. These are coalesced into the AlL 4E-model, that is described in the result. The AIL 4E-model describes a kind of progression of activities and understandings that is based on experience of that studying learning and developing pedagogical concepts is a matter of studying and involving activities where people meet. We see the social actions and activities as vital to embrace since this is where experiences and knowledge are brought to life. Therefore, in this paper, learning and knowledge are seen as an integrated part of human activity, which involves language, communication, thought and actions situated in different activities and where learning and knowledge only can be seen and understood in relation to these contexts.

From a WIL-perspective, exchange includes activities such as a guest-lecturer, internship or co-op, can be seen as the first level of WIL. What we can see is that exchange-activities actually have great impact on learning processes and how people conceive relations between expectations, contents and educational activities. Enlarge means to encourage students to make their experiences visible, to challenge it against others experiences, share it and by question experienced perspectives, institutional discourses and those "taken for granted" that surround us, activities such as internship or co-op, lifts to the next WIL-level. The participants, teachers and students, knowledge are mirrored when they mediate experience-based meaning in and about situations. But, as we argue, the participants have extended their knowledge from those situations to understanding the significance of the theoretical and practical meanings in other situations. The ways in which exchange-activities are performed they enhance enlarged learning processes among the participants. In this sense, the exchange-activities serve as very concrete tools that distribute concepts, experiences and expectations not only as to what to do and how to do it, but also when to perform tasks. This professional knowledge only becomes visible in the borderland between the theoretical and practical meaning and the activity that the participants turn their attention to, which is about to evolve the knowledge. Moreover, by scrutinizing and making patterns of knowledge and learning visible, this becomes a way to develop knowledge about work-integrated learning.

One can, like Timmermans, Bowker and and Star [15] contend, see technologies as means for making sure that the learning processes actually has been performed, as well as simultaneously ascribe them as actors in a joint activity. From our findings we can see how categorized information from different sources, like digital networks and actors often can be used in new combinations in new situations. This forms a kind of indexicality in the use of information, which simultaneously constitutes the learning processes in the activity is an extended learning. But this extended learning is not built into 
the source or actor; here, rather, it is a part of WIL-knowledge, or WIL-process to make it visible and transparent. Moreover, since activities, purposes and knowledge needs cannot be predicted, WILcompetences affect in the way new information is used in new evolving learning processes.

Empirically we philosophically support that students and teachers approach new knowledge unconditionally, meaning that there cannot be a fixed hierarchy in meaning making processes. That means that from a WIL-perspective a particular (category) of information or knowledge does not necessarily count more than any other, it rather depends on contextual factors. By providing access to information from different perspectives WIL admits, and actively encourage new combinations of information to make sense in situ. What makes sense in a situation is to a great extent a matter of how students and teachers together manage to re-contextualize information. So, what Bateson [18] so lucidly describes is that, even though thinking and creating a story implies a structure, the structure itself does not control the thinking that takes place.

A most reasonable question is what the above means for the development of knowledge, or what the individual development of knowledge in different social practices means for collective learning processes, is organized and maintained through formal education. The learning and teaching of a student involves not only learning a number of intellectual or practical skills, but also, as we argue, participation in a community where norms, values and expectations concerning the studies are included. We believe that these norms, values and expectations need to be expressed in the individuals' actions and are strongly related to higher education as an activity system.

We are now in a situation that in many aspects is a transformations of higher education where life long learning cannot be seen only as a possibility, it should rather be seen as a necessity for most professionals. The crossing of institutional and international boarders and the introduction of digital technologies in have an extensive impact on organization, coordination and communication, and are of particular interest in WIL.

\section{REFERENCES}

[1] Barnett R. "University knowledge in an age of supercomplexity". Higher Education, 40, p. 409422, (2000).

[2] Novotny H., Scott P, Gibbons M. "Rethinking Science: knowledge and the public in an age of uncertainty". Cambridge: Polity Press (2001).

[3] Betts K, Lewis M, Dressler A, Svensson L. in Asia-Pacific Journal of Cooperative Education 10(2), p. 99-119 (2009).

[4] Kjellén, B. and Svensson, L. "Work-Integrated Learning in the Classroom," in WACE 10thInternational Symposium on Cooperative \& Work-Integraded Education. Trollhättan, Sweden, (2014).

[5] Gellerstedt, M. Johansson, K. and Winman, T. "Work Integrated Learning: a Marriage Between Academia and Working Life," in Journal of Systemics, Cybernetics and Informatics, vol. 13, no. 6, pp. 38-46, (2015).

[6] Dewey, J. "Textbook series in education. Democracy and education: An introduction to the philosophy of education". New York: Macmillan Publishing, (2016).

[7] Hooker, M. (1997). "The transformation of higher education. The learning revolution". Boston, MA: Anker Publishing Company, Inc. (2003).

[8] Lave, J., \& Wenger, E. "Situated learning: Legitimate peripheral participation". Cambridge university press, (1991).

[9] Finn, K. L. "The Spaces Between: Toward a New Paradigm for Cooperative Education" in Journal of Cooperative Education, 32(2), 36-45, (1997).

[10] Billett S. "Realising the educational worth of integrating work experiences in higher education". In Journal Studies in Higher Education 34(7), 827-843, (2009).

[11] Biggs, J. and K. Collis. "Evaluating the Quality of Learning: The SOLO Taxonomy" (New York: Academic Press (1982). 
[12] Hughes J., Thomas R., Scharber C. "Assessing Technology Integration: The Rat Replacement, Amplification, and Transformation - Framework" in the Society for Information Technology \& Teacher Education International Conference, March 19, 2006 in Orlando, Florida, ISBN 978-1-880094-58-7 Publisher: Association for the Advancement of Computing in Education (AACE) Chesapeake, VA, (2006).

[13] Puentedura, R. "Learning, Technology, and the SAMR Model: Goals, Processes, and Practice." (2014) Retrieved from http://www.hippasus.com/rrpweblog/archives/2014/06/29/LearningTechnologySAMRModel.pdf

[14] Hamilton E., Rosenberg J. and Akcaoglu. "The Substitution Augmentation Modification Redefinition (SAMR) Model: a Critical Review aand Suggestions for its Use" in TechTrends: For Leaders in Education \& Training, p. 433-441. (2016). Retrieved from https://link.springer.com/article/10.1007/s11528-016-0091-y

[15] Timmermans, S., Bowker, G. S., \& Leigh Star, S. "The architecture of difference: visibility, control and comparability in building a nursing interventions classification". In Berg, M. \& Mol, A. (Eds.), Differences in medicine: unraveling practices, techniques, and bodies (202-225). London, UK: Duke University Press, (1998).

[16] Gibson, J. J. "The ecological approach to visual perception". Boston: Houghton Mifflin, (1979).

[17] Gaver, W.W. "Technology affordances". In ACM, CHI '91 Proceedings of the SIGCHI conference on Human factors in computing systems: Reaching through technology, 79-84, (1991).

[18] Bateson, G. "Mind and Nature. A Necessary Unity". Ceresskill, New Jersey: Hampton Press. (2002). 